\title{
A prospective evaluation of thiamine and magnesium status in relation to clinicopathological characteristics and 1-year mortality in patients with alcohol withdrawal syndrome
}

\author{
Donogh Maguire ${ }^{1,2^{*} \mathbb{D}}$, Dinesh Talwar ${ }^{3}$, Alana Burns $^{3,4}$, Anthony Catchpole ${ }^{3}$, Fiona Stefanowicz ${ }^{3}$, \\ Gordon Robson ${ }^{1}$, David P. Ross ${ }^{1,2}$, David Young ${ }^{5}$, Alastair Ireland ${ }^{1}$, Ewan Forrest ${ }^{6}$, Peter Galloway ${ }^{4}$, \\ Michael Adamson ${ }^{1}$, Eoghan Colgann ${ }^{1}$, Hannah Bell ${ }^{1}$, Lesley Orr ${ }^{1}$, Joanna-Lee Kerr ${ }^{1}$, Xen Roussis ${ }^{1}$ \\ and Donald C. McMillan²
}

\begin{abstract}
Background: Alcohol withdrawal syndrome (AWS) is routinely treated with B-vitamins. However, the relationship between thiamine status and outcome is rarely examined. The aim of the present study was to examine the relationship between thiamine and magnesium status in patients with AWS.

Methods: Patients $(n=127)$ presenting to the Emergency Department with AWS were recruited to a prospective observational study. Blood samples were drawn to measure whole blood thiamine diphosphate (TDP) and serum magnesium concentrations. Routine biochemistry and haematology assays were also conducted. The Glasgow Modified Alcohol Withdrawal Score (GMAWS) measured severity of AWS. Seizure history and current medications were also recorded.

Results: The majority of patients (99\%) had whole blood TDP concentration within/above the reference interval $(275-675 \mathrm{ng} / \mathrm{gHb}$ ) and had been prescribed thiamine (70\%). In contrast, the majority of patients (60\%) had low serum magnesium concentrations ( $<0.75 \mathrm{mmol} / \mathrm{L}$ ) and had not been prescribed magnesium (93\%). The majority of patients (66\%) had plasma lactate concentrations above $2.0 \mathrm{mmol} / \mathrm{L}$. At 1 year, 13 patients with AWS had died giving a mortality rate of $11 \%$. Male gender $(p<0.05), B M l<20 \mathrm{~kg} / \mathrm{m}^{2}(p<0.01)$, GMAWS max $\geq 4(p<0.05)$, elevated plasma lactate $(p<0.01)$, low albumin $(p<0.05)$ and elevated serum CRP $(p<0.05)$ were associated with greater 1-year mortality. Also, low serum magnesium at time of recruitment to study and low serum magnesium at next admission were associated with higher 1 -year mortality rates, $(84 \%$ and $100 \%$ respectively; both $p<0.05)$.

Conclusion: The prevalence of low circulating thiamine concentrations were rare and it was regularly prescribed in patients with AWS. In contrast, low serum magnesium concentrations were common and not prescribed. Low serum magnesium was associated more severe AWS and increased 1-year mortality.
\end{abstract}

\footnotetext{
*Correspondence: Donogh.Maguire@glasgow.ac.uk

${ }^{1}$ Emergency Medicine Department, Glasgow Royal Infirmary, 84 Castle

Street, Glasgow G4 OSF, Scotland, UK

Full list of author information is available at the end of the article
} 
Keywords: Alcohol withdrawal syndrome (AWS), Serum magnesium concentration, Circulating thiamine diphosphate (TDP), Pseudo-hypoxia, Plasma lactate concentrations, Glasgow modified alcohol withdrawal scale (GMAWS), Seizure kindling, 1-year mortality

\section{Background}

Despite public health measures, alcohol consumption has continued to rise in the USA and UK over the past three decades [1-3]. In the USA, the number of alcohol related deaths is reported to have increased by $35 \%$ between 2007 and 2017 [4], while Scotland is reported to have the highest alcohol related death rate in the UK [5]. Despite these recent epidemiological reports, there is a paucity of data available in the literature related to mortality for patients following an episode of alcohol withdrawal syndrome (AWS) [6].

Alcohol exerts direct and indirect effects on cellular energy metabolism and alcohol use disorder (AUD) is a complex psychological and pathophysiological problem $[7,8]$. Nutritional and social factors may be protective or contributory, however a threshold may be reached beyond which alcohol related compromise of oxidative resilience manifests in accelerated organ/system specific final common pathways of biochemical and clinical deterioration [7, 9]. The occurrence of alcohol withdrawal syndrome (AWS) may represent the crossing of that threshold [9].

Standard treatment of AWS is predicated upon early provision of benzodiazepine treatment to ameliorate symptoms and prevent progression to AWS seizures, mainly by restoring the balance between the N-methylD-aspartate (NMDA) and gamma-aminobutyric acid (GABA) receptor activity at the synapse [10, 11]. Benzodiazepines replicate the GABA enhancing effect of alcohol on the CNS, thus down-regulating excitatory NMDA activity and preventing progression of alcohol withdrawal syndrome and seizures $[10,11]$. In addition, there is empirical provision of thiamine in the form of B-vitamins over the period of hospitalization. For example, B-vitamins are administered to mitigate against the risk of thiamine deficiency related neurodegenerative conditions (e.g. Wernicke-Korsakoff syndrome) that are known to occur in alcohol use disorder patients due to compromise of key enzymes involved in intermediary metabolism [12, 13]. Thiamine in the form of thiamine diphosphate (TDP) is required as a co-factor for pyruvate dehydrogenase (PDH) and alpha ketoglutaric acid dehydrogenase (KGDH), both key enzymes in Krebs cycle (Fig. 1). Thiamine also requires magnesium for absorption from the GI tract [14], activation to its active form (TDP) [15] and for optimal activity of thiamine dependent enzymes within the cell $[16,17]$. Thiamine and/or magnesium deficiency may compromise these enzymes and result in altered metabolism of glucose and increased lactate production (Fig. 2) [18, 19]. Therefore, in the context of normal partial pressure tissue oxygen concentrations and in the absence of an inflammatory response or intense skeletal muscle activity (e.g. alcohol withdrawal seizure), thiamine and/or magnesium deficiency mediated increase in metabolism of glucose to lactate may represent pseudo-hypoxic disruption of normal glucose metabolism $[7,20]$.

Despite the prevalence of alcohol dependence in the western world, accurate data for thiamine deficiency is not available, with thiamine deficiency recorded as being between $30-80 \%$ in the AUD population [21, 22]. Furthermore, there is a paucity of accurate evidence to guide clinicians regarding the dose and duration of thiamine treatment or prophylaxis for Wernicke's encephalopathy (WE) [22, 23]. It has been observed that WE can occur in the context of apparently normal blood thiamine levels [24]. Case reports have accrued over the past four decades, which point to a role for magnesium in patients who remain refractory to thiamine treatment, and respond to concurrent administration of intravenous magnesium [25-27]. Despite these case reports and the biochemical evidence in favor of an enhanced response to thiamine therapy when administered with magnesium $[16,17,28,29]$, the potential relationship between thiamine and magnesium has remained largely unexplored in a clinical context.

We recently reported in a retrospective study that patients who experienced an episode of alcohol withdrawal syndrome received thiamine supplementation although thiamine diphosphate (TDP) concentrations were not determined. In contrast, serum magnesium concentrations were measured and patients who had low serum magnesium concentrations $\left(\mathrm{Mg}^{2+}<0.75 \mathrm{mmol} / \mathrm{L}\right)$ were rarely supplemented and were four times more likely to die at 1 year [9]. Furthermore, there was little supplementation of such low magnesium concentrations following discharge from hospital. Therefore, treatment of AUD, based on combined thiamine and magnesium supplementation is not well standardized in either the acute or chronic setting.

To validate the above findings, a prospective study was carried out of the relationship between circulating concentrations of thiamine and magnesium, the substrates and products of intermediary metabolism, the 


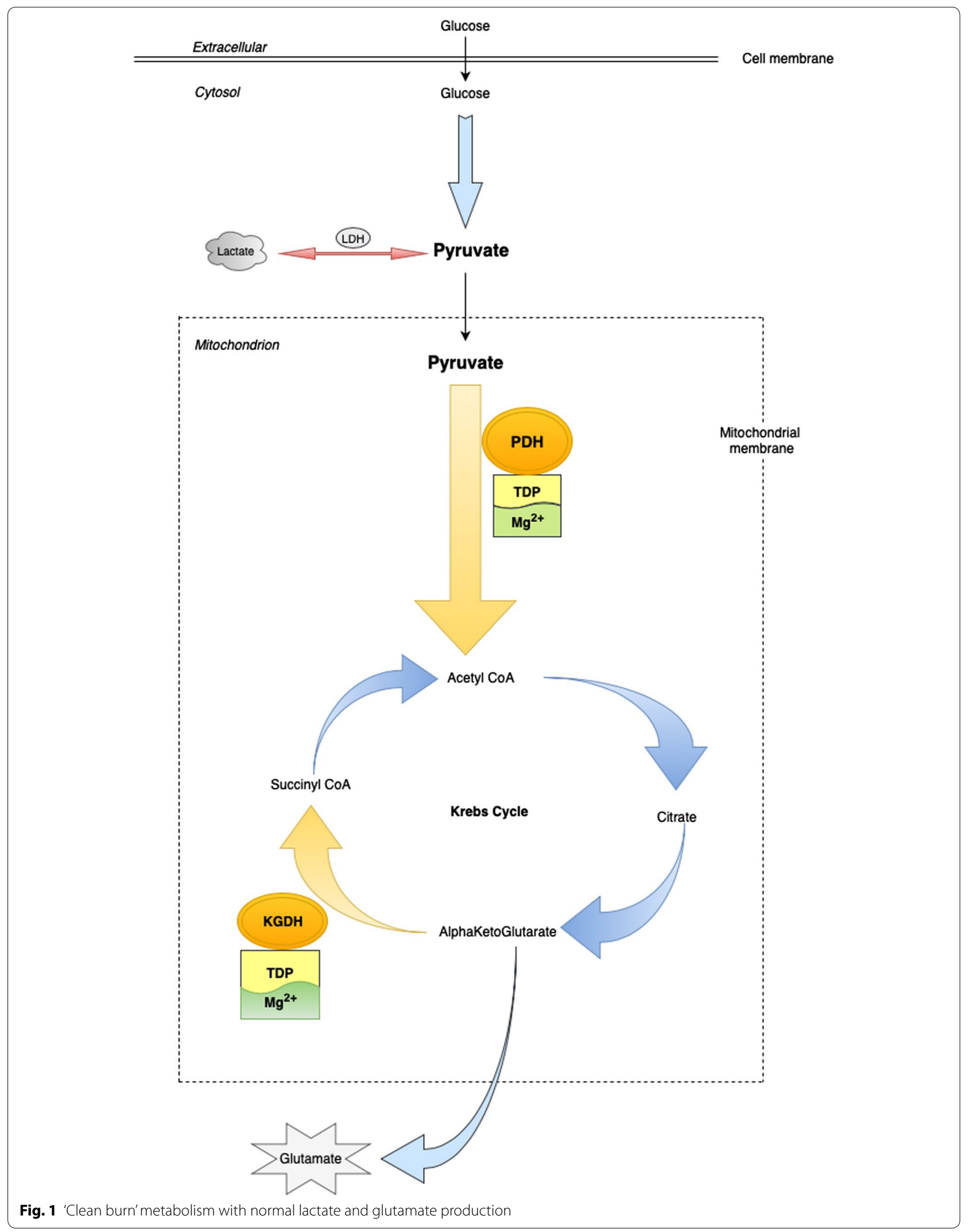



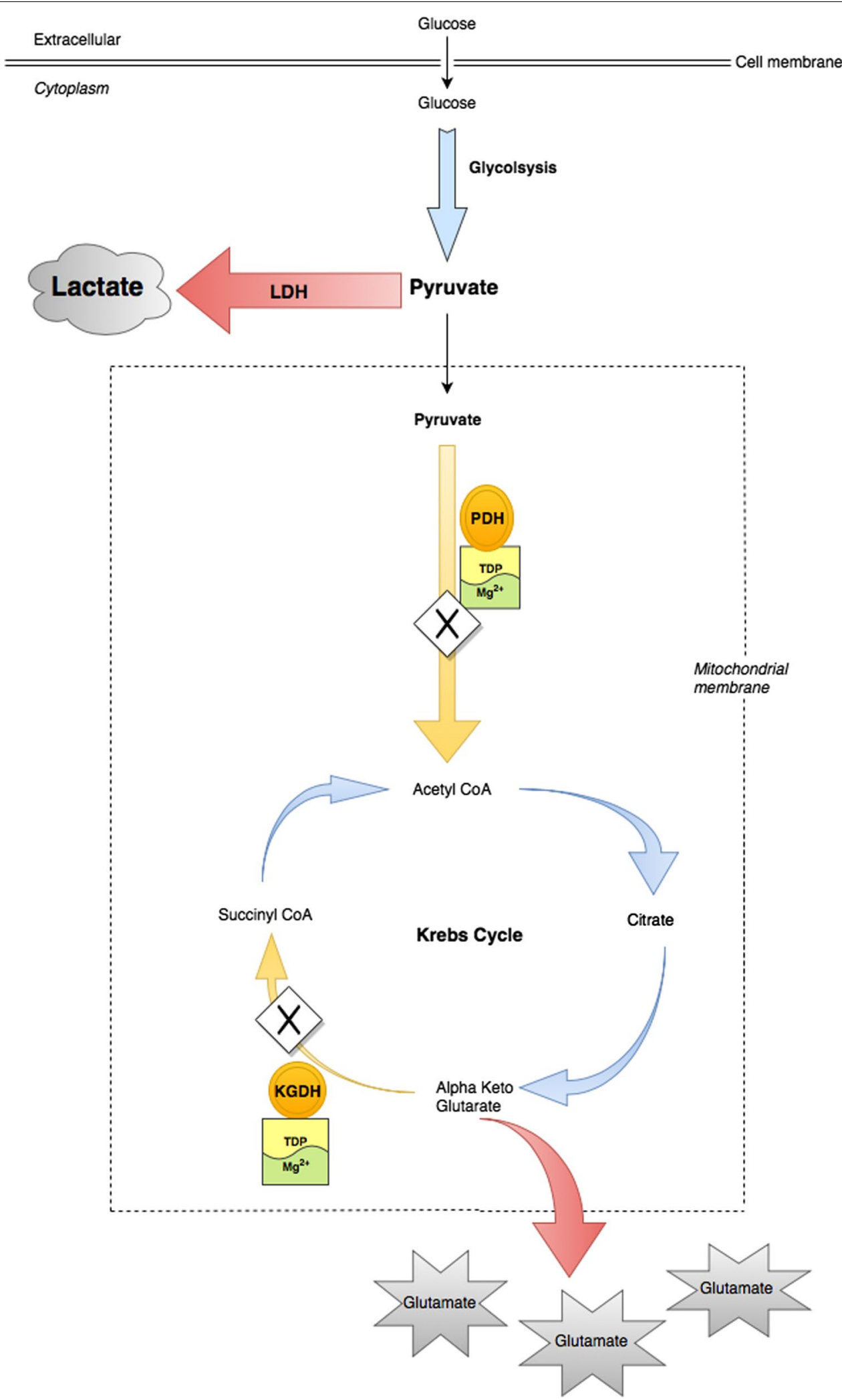

Fig. 2 'Dirty burn' metabolism: Pseudo-hypoxic dysregulation of glucose metabolism with increased production of lactate and excitatory glutamate in patients with AWS 
clinicopathological characteristics of AWS and 1-year mortality in patients with AWS.

\section{Patients and methods}

The study took place in the Emergency Department of Glasgow Royal Infirmary (GRI) between December 2016 and February 2018. GRI is a university teaching hospital that serves an urban population with a high burden of socio-economic deprivation and offers the full spectrum of adult acute receiving specialties to patients over 16 years old [30,31]. The study was approved by the West of Scotland Research Ethics Committee (WoS REC: 16/ WS/0162).

Age, sex, BMI and documented evidence of AWS were considered minimal criteria for inclusion $(n=127)$. Patients displaying clinical signs or reporting symptoms consistent with AWS at presentation to triage in the Emergency Department were approached in triage, or as soon as possible thereafter, regarding consent for participation in the study. As per routine clinical practice in the Emergency Department at GRI, patients were scored on the Glasgow Modified Alcohol Withdrawal Scale (GMAWS) and provided with standard benzodiazepine treatment for AWS (Fig. 3).

GMAWS is a validated score of severity of alcohol withdrawal syndrome that allocates a score (0-2) to five clinical characteristics (tremor, anxiety, sweating, orientation, hallucinations) (Fig. 3) [6]. GMAWS determines the dose of benzodiazepine treatment that is titrated and the time interval to re-administering the GMAWS scoring tool according to the score achieved (i.e. the severity of alcohol withdrawal). Diazepam (P.O.) or lorazepam (P.O. or I.V.) is administered as per GMAWS protocol. For the purposes of this study a 'diazepam equivalent dose' of benzodiazepine treatment was recorded, where diazepam $10 \mathrm{mg}$ was equivalent to lorazepam $1 \mathrm{mg}$. A GMAWS $\geq 4$ is considered severe, and is approximately equivalent to a Clinical Institute Withdrawal Assessment-Alcohol Revised (CIWA-Ar) scale $\geq 16$ [6].

Bloods were drawn for routine biochemistry/haematology and study samples prior to administration of parenteral thiamine $\left(\right.$ Pabrinex $^{\circledR}$ ). Pabrinex ${ }^{\circledR}$ is a two-vial multi-vitamin preparation that is administered intravenously in $100 \mathrm{ml}$ normal saline over $30 \mathrm{~min}$. Pabrinex ${ }^{\circledR}$ contains thiamine hydrochloride $250 \mathrm{mg}$, nicotinamide $160 \mathrm{mg}$, pyridoxine hydrochloride $50 \mathrm{mg}$, riboflavin $4 \mathrm{mg}$ and ascorbic acid $500 \mathrm{mg} / 10 \mathrm{~mL}$ [32]. A standard dose is 2 pairs of vials 1 and 2, administered TDS for 2 days [32-34].

Whole blood EDTA samples for thiamine diphosphate measurement were frozen at $-70{ }^{\circ} \mathrm{C}$ and analyzed within 10 days of being drawn. Measurement of thiamine diphosphate in whole blood involved HPLC isocratic separation with post-column derivatization using

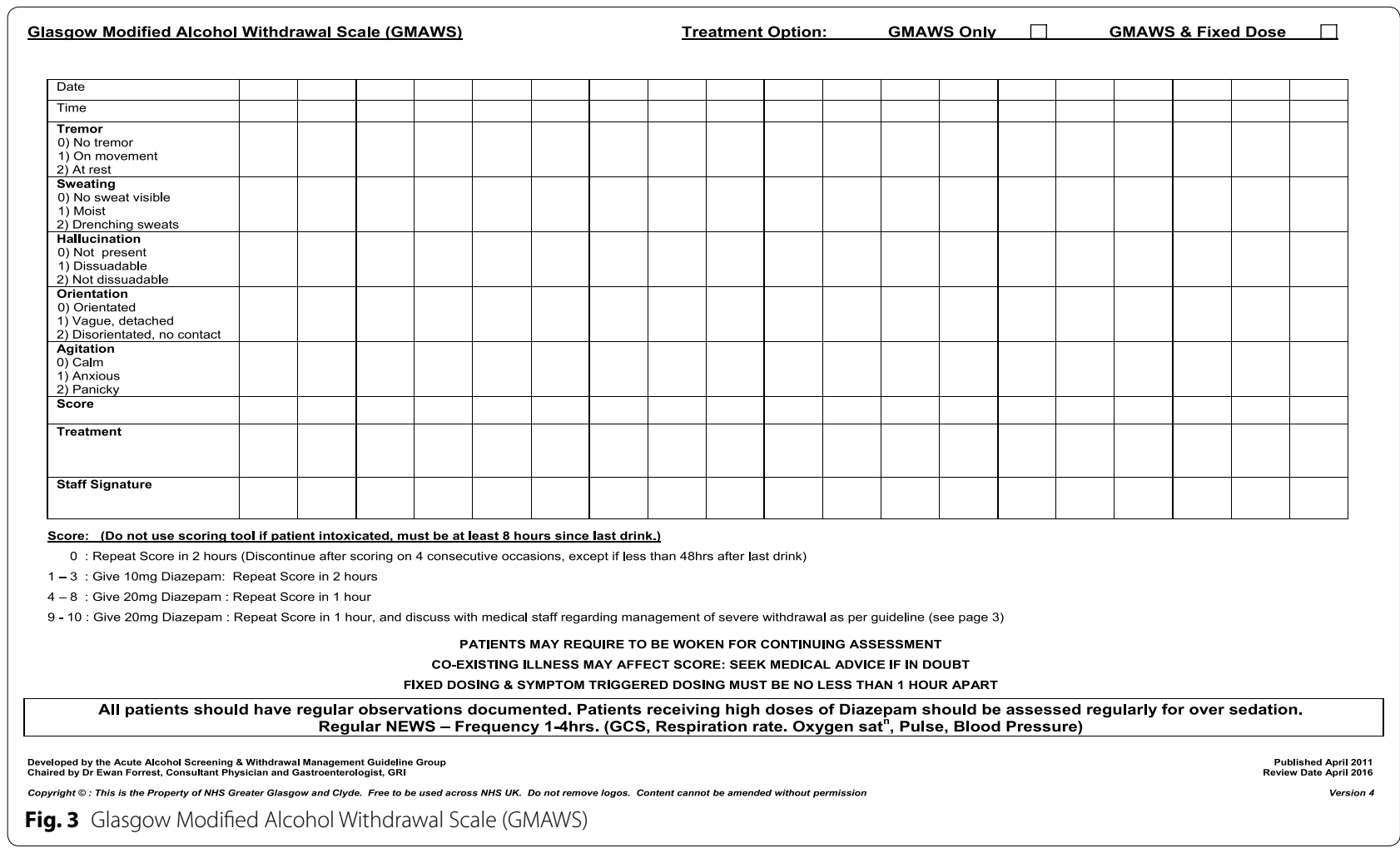


sodium hydroxide and potassium ferricyanide and fluorescent detection. Results were expressed as nanogram of thiamine diphosphate per gram of haemoglobin $(\mathrm{ng} / \mathrm{gHb})$ [35].

A questionnaire was administered regarding recent weight loss, recent difficulty walking, smoking history, previous AWS episodes, previous AWS related seizures and use of 'over the counter' vitamin or magnesium supplements. Data relating to daily alcohol consumption were also recorded. Electronic patient records were also examined for data relating to past medical history and current medications.

Following completion of the study, electronic patient records were re-examined to record serum magnesium concentrations in patients during their next unplanned admission. Electronic patient records were also re-examined to record 1-year mortality in patients who had been entered into the study.

Standard thresholds were applied to the data. Continuous data were analyzed using the Mann-Whitney U test and categorical data were analyzed using the Chi squared test. Continuous data are presented as a median value and related inter-quartile range (IQR). Binary logistic regression analysis data was undertaken to examine the relationship between the severity of AWS (GMAWS $<1 \geq 4$ ) and independent variables. Data were analyzed in SPSS (Version 25.0. SPSS Inc., Chicago, IL, USA).

\section{Results}

Only 3 patients who were screened for inclusion in the study at triage were found to have on-going active evidence of delirium. These patients were not recruited to the study, as they lacked capacity to consent. All patients $(n=127)$ recruited to the study fulfilled the criteria for inclusion with age, sex, BMI and documented evidence of alcohol withdrawal syndrome. Patients with 2 observations $(n=12)$ were excluded, leaving 115 patients for analysis.

The majority of patients (85\%) reported previous episodes of alcohol withdrawal syndrome and had a documented history of previous alcohol withdrawal seizure $(60 \%)$. Of the patients recruited to the study, $28 \%$ had suffered a tonic-clonic seizure within the 12-h period prior to presentation to the Emergency Department and 97\% of these patients had a documented history of previous alcohol withdrawal seizures. Patients who had a previous history of AWS had higher GMAWS scores $(\mathrm{p}<0.05)$, higher benzodiazepine requirement $(p<0.001)$ and more frequent previous admissions $(\mathrm{p}<0.01)$ than those who had not previously experienced AWS.

Twenty-five patients (22\%) recruited to the study progressed to develop delirium tremens and three patients
(3\%) suffered a tonic-clonic seizure during the course of the study related admission.

The clinicopathological characteristics are shown in Table 1 . The majority of patients were $<50$ years old (65\%), male (76\%), not underweight $(80 \%)$, had a severe alcohol withdrawal score (GMAWS max score $\geq 4)(65 \%)$ and the total 'diazepam-equivalent' dose of benzodiazepine (BDZ) administered was more than $120 \mathrm{mg}$ (51\%). Of the laboratory analysis, the majority of patients had bilirubin (57\%), alkaline phosphatase (67\%), albumin (76\%), CRP (56\%), AST/ALT ratio (64\%), glucose (66\%), urea $(67 \%)$, sodium $(69 \%)$, potassium $(81 \%)$, MCV $(52 \%)$ and platelets $(68 \%)$ within the laboratory reference interval. The majority of patients had been prescribed thiamine $(69 \%)$ and a proton pump inhibitor (PPi) (55\%).

The majority of patients had whole blood thiamine diphosphate concentrations (59\%) within the normal reference interval $(275-675 \mathrm{ng} / \mathrm{gHb})$ and $40 \%$ of patients had whole blood thiamine diphosphate concentrations above the reference interval ( $>675 \mathrm{ng} / \mathrm{gHb}$ ). One-third of patients $(33 \%)(n=14)$ who had whole blood thiamine diphosphate concentrations above the reference interval $(>675 \mathrm{ng} / \mathrm{gHb})(\mathrm{n}=42)$ at the time of study recruitment had been admitted to hospital and treated with parenteral thiamine within 1 month prior to the study related admission. The majority of patients (73\%) had been prescribed long-term oral thiamine supplementation $(50 \mathrm{mg}$ or $100 \mathrm{mg}$ TDS) in the community prior to entering the study. Only one of the patients $(<1 \%)$ entered into the study had a whole blood thiamine concentration below the reference interval $(<275 \mathrm{ng} / \mathrm{gHb})$.

In contrast, the majority of patients had serum magnesium concentrations that could be considered to be low $(<0.75 \mathrm{mmol} / \mathrm{L} ; 60 \%)$ and had not been prescribed magnesium $(93 \%)$. When patients from this cohort $(\mathrm{n}=81)$ were followed up at their next admission, the majority of patients (74\%) still had serum magnesium concentrations below the reference interval $(<0.75 \mathrm{mmol} / \mathrm{L})$ (median $=0.67 \mathrm{mmol} / \mathrm{L}$, IQR $0.59-0.76 \mathrm{mmol} / \mathrm{L}$, median time interval between samples $=126$ days) (see Tables 1 , 2; Fig. 4).

The majority of patients (66\%) were found to have plasma lactate concentrations above $2.0 \mathrm{mmol} / \mathrm{L}$. When patients who had experienced a seizure in the 12-hour period prior to study enrolment $(n=29)$ were excluded from the analysis, the majority $(60 \%)$ of the remaining patients $(\mathrm{n}=74)$ had plasma lactate concentrations above $2.0 \mathrm{mmol} / \mathrm{L}$. The median plasma lactate concentration for this sub-set of patients (i.e. non-seizure related alcohol withdrawal syndrome presentations) was $2.4 \mathrm{mmol} / \mathrm{L}$ (IQR $1.6-4.5 \mathrm{mmol} / \mathrm{L}$ ). The median plasma lactate concentration for patients recruited to the study with alcohol withdrawal syndrome who had experienced a seizure 
Table 1 The relationship between clinicopathological characteristics and 1-year mortality in patients with AWS ( $n=115)$

\begin{tabular}{|c|c|c|c|}
\hline & Alive $(n=102)$ & Dead $(n=13)$ & $p$-value ${ }^{1}$ \\
\hline Age (years) & $48(39-54)$ & $48(35-60)$ & 0.915 \\
\hline Male/female & $75 / 27$ & $13 / 0$ & 0.035 \\
\hline BMI $\left(\mathrm{kg} / \mathrm{m}^{2}\right)$ & $22.6(20.9-26.2)$ & $21.9(18.8-29.2)$ & 0.473 \\
\hline \multicolumn{4}{|l|}{ Clinical } \\
\hline Alcohol intake (U/week) ${ }^{a}$ & $205(134-280)$ & $280(140-350)$ & 0.390 \\
\hline GMAWS (at presentation) & $4(3,4)$ & $4(4-5)$ & 0.077 \\
\hline GMAWS max & $4(3-5)$ & $5(4-6)$ & 0.090 \\
\hline GMAWS $\max (<4 / \geq 4)$ & $38 / 63$ & $1 / 12$ & 0.033 \\
\hline BDZ total $(\mathrm{mg})$ & $130(50-240)$ & $230(55-320)$ & 0.148 \\
\hline Smoker (yes/no) & $75 / 24$ & $9 / 4$ & 0.611 \\
\hline Recent weight loss (yes/no) & $65 / 28$ & $11 / 1$ & 0.114 \\
\hline Gait disturbance (yes/no) & $83 / 18$ & $12 / 1$ & 0.358 \\
\hline \multicolumn{4}{|l|}{ Laboratory } \\
\hline Bilirubin (umol/L) & $16(10-28)$ & $31(13-75)$ & 0.019 \\
\hline Alk phos $(U / L)$ & $106(92-137)$ & $130(95-180)$ & 0.154 \\
\hline Albumin (g/L) & $39(36-42)$ & $37(27.5-40)$ & 0.106 \\
\hline $\mathrm{CRP}(\mathrm{mg} / \mathrm{L})$ & $4(2-11)$ & $17(7-30)$ & 0.004 \\
\hline AST & $58(34-98)$ & $78(29-131)$ & 0.634 \\
\hline $\mathrm{ALT}$ & $38(25-61)$ & $35(18-53)$ & 0.185 \\
\hline AST:ALT & $1.6(1.0-2.2)$ & $1.9(1.5-3.4)$ & 0.038 \\
\hline Urea (mmol/L) & $3.4(2.6-4.8)$ & $3.2(2.5-5.4)$ & 0.569 \\
\hline Sodium (mmol/L) & $137(134-140)$ & $138(136-141)$ & 0.280 \\
\hline Potassium (mmol/L) & $4.0(3.7-4.4)$ & $4.0(3.5-4.5)$ & 0.555 \\
\hline Serum magnesium (mmol/L) & $0.72(0.62-0.80)$ & $0.53(0.48-0.72)$ & 0.006 \\
\hline Plasma H $H^{+}(\mathrm{nmol} / \mathrm{L})$ & $37(33-40)$ & $33(27-40)$ & 0.175 \\
\hline Plasma $\mathrm{HCO}_{3}{ }^{-}(\mathrm{mmol} / \mathrm{L})$ & $27(25-32)$ & $28(24-35)$ & 0.745 \\
\hline$M C V(f l)$ & $95.4(90.6-99.7)$ & $100.4(93.1-106.7)$ & 0.059 \\
\hline Platelets $\left(10^{9} / \mathrm{L}\right)$ & $239(143-295)$ & $175(78-240)$ & 0.092 \\
\hline Whole blood TDP (ng/gHb) & $595(509-825)$ & $670(391-791)$ & 0.720 \\
\hline LDH (U/L) & $257(208-325)$ & $272(220-369)$ & 0.373 \\
\hline Glucose (mmol/L) & $5.8(5.3-7.5)$ & $6.9(5.9-7.7)$ & 0.183 \\
\hline Lactate $(\mathrm{mmol} / \mathrm{L})$ & $2.3(1.5-4.2)$ & $3.8(2.6-7.2)$ & 0.011 \\
\hline Follow-up'next admission'serum magnesium (mmol/L) & $0.68(0.59-0.76)$ & $0.61(0.49-0.67)$ & 0.020 \\
\hline \multicolumn{4}{|l|}{ Medications } \\
\hline Thiamine (yes/no) & $77 / 23$ & $2 / 11$ & 0.978 \\
\hline Magnesium (yes/no) & $8 / 88$ & $13 / 0$ & 0.282 \\
\hline PPi (yes/no) & $59 / 40$ & $4 / 9$ & 0.506 \\
\hline Diuretic (yes/no) & $5 / 91$ & $4 / 9$ & 0.002 \\
\hline \multicolumn{4}{|l|}{ Admission profile } \\
\hline Admitted within previous month (yes/no) & $23 / 75$ & $3 / 10$ & 0.975 \\
\hline ED presentations within 12 months & $2(1-5)$ & $3(2-7)$ & 0.315 \\
\hline Total number of admissions & $14(6-32)$ & $14(4-57)$ & 0.466 \\
\hline Length of stay (days) & $4(3-7)$ & $8(5-10)$ & 0.027 \\
\hline
\end{tabular}

${ }^{1}$ Continuous data were analysed with Mann-Whitney $U$ test and categorical data were analysed with Chi squared test

a Alcohol intake-alive: $\mathrm{n}=54$; dead: $\mathrm{n}=3$ 
Table 2 The relationship between circulating magnesium concentrations and clinicopathological characteristics in patients with alcohol withdrawal syndrome $(n=111)$

\begin{tabular}{|c|c|c|c|}
\hline & \multicolumn{2}{|c|}{ Serum magnesium (mmol/L) } & \multirow[t]{2}{*}{$p$-value ${ }^{1}$} \\
\hline & $\geq 0.75(n=46)$ & $<0.75(n=65)$ & \\
\hline Age (years) & $46(35-49)$ & $48(40-54)$ & 0.139 \\
\hline Male/female & $33 / 13$ & $53 / 12$ & 0.226 \\
\hline BMI $\left(\mathrm{kg} / \mathrm{m}^{2}\right)$ & $22.5(20.9-24.8)$ & $22.7(20.5-27.1)$ & 0.571 \\
\hline Dead at 1-year (yes/no) & $2 / 44$ & $11 / 54$ & 0.043 \\
\hline \multicolumn{4}{|l|}{ Clinical } \\
\hline Alcohol intake (U/week) ${ }^{a}$ & $210(145-280)$ & $168(42-420)$ & 0.259 \\
\hline GMAWS (at presentation) & $3(2-4)$ & $4(3-5)$ & 0.006 \\
\hline GMAWS max & $3(2-4)$ & $4(4-6)$ & 0.001 \\
\hline BDZ total (mg) & $100(40-210)$ & $180(50-290)$ & 0.335 \\
\hline Smoker (yes/no) & $31 / 13$ & $50 / 14$ & 0.368 \\
\hline Recent weight loss (yes/no) & 29/14 & $46 / 14$ & 0.302 \\
\hline Gait disturbance (yes/no) & $35 / 11$ & $56 / 8$ & 0.120 \\
\hline \multicolumn{4}{|l|}{ Laboratory } \\
\hline Bilirubin (umol/L) & $12(8-20)$ & $17(13-41)$ & $<0.001$ \\
\hline Alk phos (U/L) & 101 (90-138) & $114(94-140)$ & 0.430 \\
\hline Albumin (g/L) & $39(36-43)$ & $38(36-41)$ & 0.168 \\
\hline CRP (mg/L) & $4.5(1-10.5)$ & $5(2-14.3)$ & 0.303 \\
\hline AST & $44(3175)$ & $66(41-213)$ & 0.015 \\
\hline ALT & $37(24-61)$ & $38(25-60)$ & 0.854 \\
\hline AST:ALT & $1.4(1.0-1.8)$ & $1.6(1.3-2.8)$ & 0.004 \\
\hline Urea $(\mathrm{mmol} / \mathrm{L})$ & $3.3(2.6-5.2)$ & $3.3(2.5-4.9)$ & 0.593 \\
\hline Sodium (mmol/L) & $138(134-141)$ & $138(134-139)$ & 0.422 \\
\hline Potassium (mmol/L) & $4.1(3.7-4.5)$ & $4.0(3.6-4.3)$ & 0.437 \\
\hline Plasma $\mathrm{H}^{+}(\mathrm{nmol} / \mathrm{L})$ & $39(35-40)$ & $36(31-39)$ & 0.013 \\
\hline Plasma $\mathrm{HCO}_{3}^{-}(\mathrm{mmol} / \mathrm{L})$ & $29(24-33)$ & $27(25-31)$ & 0.812 \\
\hline $\mathrm{MCV}(\mathrm{fl})$ & $95.2(90.9-99.6)$ & $95.7(91.2-100.4)$ & 0.418 \\
\hline Platelets $\left(10^{9} / \mathrm{L}\right)$ & $256(165-312)$ & $204(117-282)$ & 0.020 \\
\hline Follow-up'next admission' serum magnesium (mmol/L) & $0.73(0.66-0.79)$ & $0.61(0.55-0.68)$ & $<0.001$ \\
\hline Whole blood TDP (ng/gHb) & $642(500-855)$ & $591(501-775)$ & 0.305 \\
\hline $\mathrm{LDH}(\mathrm{U} / \mathrm{L})$ & $240(209-308)$ & $269(213-358)$ & 0.333 \\
\hline Glucose (mmol/L) & $5.8(5.4-7.2)$ & $6.2(5.3-7.9)$ & 0.477 \\
\hline Lactate (mmol/L) & $2.3(1.3-3.4)$ & $2.9(1.9-5.9)$ & 0.023 \\
\hline \multicolumn{4}{|l|}{ Medications } \\
\hline Thiamine (yes/no) & $34 / 12$ & $51 / 13$ & 0.478 \\
\hline Magnesium (yes/no) & $5 / 41$ & $3 / 57$ & 0.259 \\
\hline PPi (yes/no) & $26 / 20$ & $39 / 24$ & 0.573 \\
\hline Diuretic (yes/no) & $1 / 44$ & $8 / 53$ & 0.048 \\
\hline \multicolumn{4}{|l|}{ Admission profile } \\
\hline Admitted within previous month (yes/no) & $14 / 31$ & $11 / 52$ & 0.077 \\
\hline ED presentations within 12 months & $3(1-7)$ & $2(0-36)$ & 0.923 \\
\hline Total number of admissions & $15(6-33)$ & $14(0-172)$ & 0.646 \\
\hline Length of stay (days) & $4(3-7)$ & $5(1-29)$ & 0.171 \\
\hline
\end{tabular}

1 Continuous data were analysed with Mann-Whitney $\mathrm{U}$ test and categorical data were analysed with Chi squared test

a Alcohol intake: $\mathrm{Mg}^{2+} \geq$ and $<0.75 \mathrm{mmol} / \mathrm{L}: \mathrm{n}=22 ; \mathrm{n}=32$ 


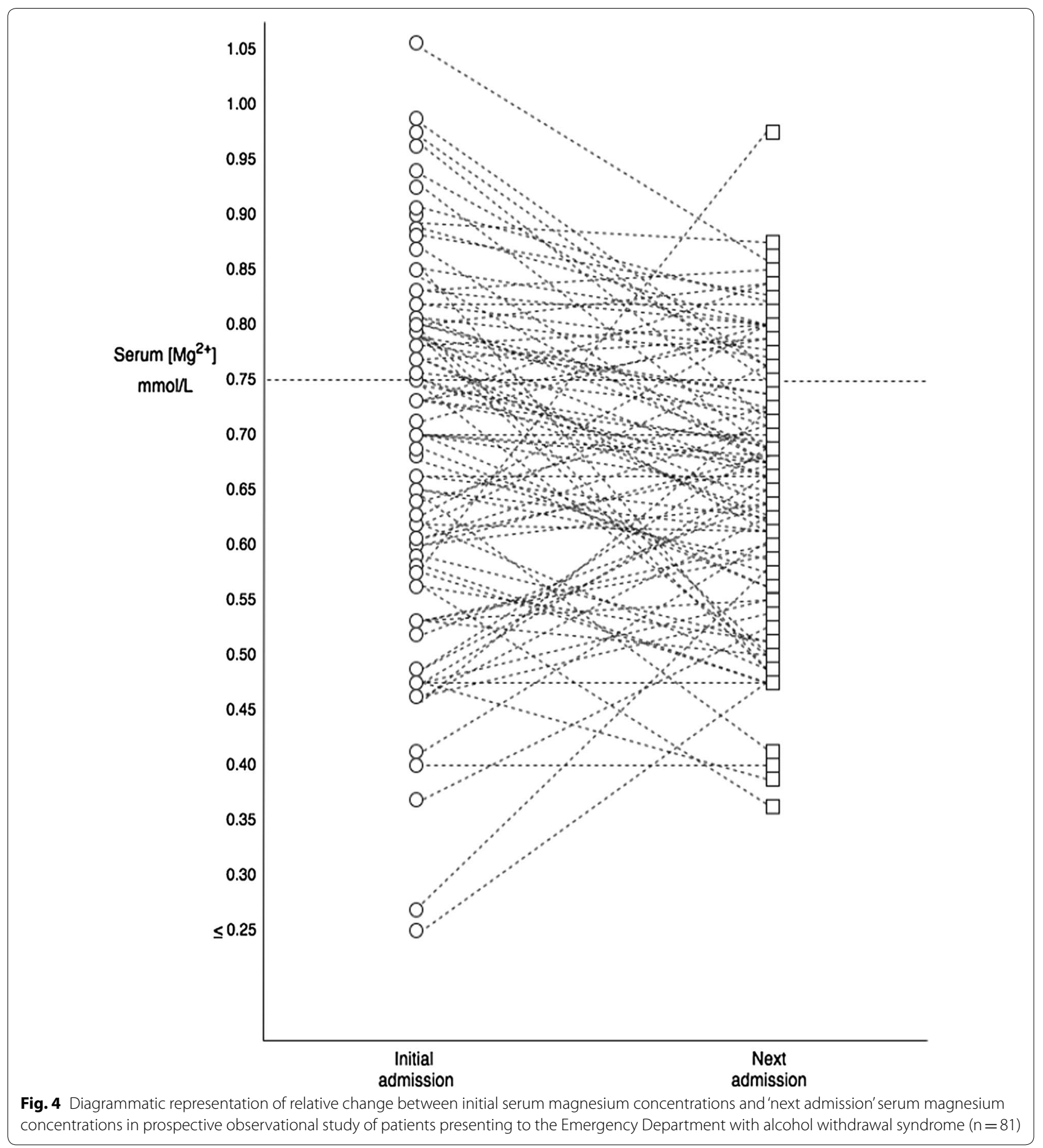

within $12 \mathrm{~h}$ of presentation $(\mathrm{n}=29)$ was $2.5 \mathrm{mmol} / \mathrm{L}$ (IQR 1.7-14.6 mmol/L). Serum magnesium concentrations were significantly associated with plasma lactate concentrations $\left(\mathrm{r}_{\mathrm{s}}=-0.234, \mathrm{p}<0.05\right)$.

At 1 year, 13 patients had died giving a mortality rate of $11 \%$. The relationship between 1 -year mortality and clinicopathological characteristics are shown in Table 1. On univariate analysis, male gender $(\mathrm{p}<0.05)$, $\mathrm{BMI}<20 \mathrm{~kg} / \mathrm{m}^{2}(\mathrm{p}<0.01)$, GMAWS $\max \geq 4 \quad(\mathrm{p}<0.05)$, elevated plasma lactate $(\mathrm{p}<0.01)$, low serum albumin $(\mathrm{p}<0.05)$, elevated serum CRP $(\mathrm{p}<0.05)$, low serum magnesium at time of recruitment to study $(\mathrm{p}<0.05)$ and 
low serum magnesium concentration at next admission $(\mathrm{p}<0.05)$ were associated with death at 1 -year.

The relationship between low serum magnesium concentrations and clinicopathological characteristics is shown in Table 2. Low serum magnesium concentrations were associated with a higher GMAWS score at presentation $(\mathrm{p}<0.01)$, higher GMAWS max $(\mathrm{p}=0.001)$, elevated hydrogen ion concentrations $(>45 \mathrm{nmol} / \mathrm{L})(\mathrm{p}<0.05)$ and death at 1-year $(\mathrm{p}<0.05)$.

Binary logistic regression analysis confirmed that patients who had low serum magnesium concentrations $(<0.75 \mathrm{mmol} / \mathrm{L})$ were 3 times more likely to have a severe episode of AWS (GMAWS $\geq 4$ ) when compared to those patients who had serum magnesium concentrations within the normal reference interval (O.R. $=3.0,95 \% \mathrm{CI}$ (1.1-8.0), $\mathrm{p}<0.05)$.

\section{Discussion}

The results of the present prospective study show that the majority of patients with AWS had thiamine concentrations within or above the normal interval. In contrast, the majority of patients had low serum magnesium concentrations at presentation. Furthermore, low serum magnesium concentrations $(<0.75 \mathrm{mmol} / \mathrm{L})$ were associated with increased risk of mortality at 1-year among patients admitted to hospital with AWS. These results highlight the importance of a low serum magnesium concentration, and its lack of treatment, in outcome of patients presenting with AWS.

It was of interest that only 1 patient $(<1 \%)$ in the cohort $(\mathrm{n}=115)$ had a baseline circulating thiamine diphosphate measurement below the reference interval $(<275 \mathrm{ng} /$ $\mathrm{gHb})$. Indeed, almost $40 \%$ of patients had circulating thiamine diphosphate concentrations above the upper limit of the reference interval (>675 ng/gHb), and had been prescribed thiamine (73\%). In contrast, approximately $60 \%$ of patients had low serum magnesium concentrations $(<0.75 \mathrm{mmol} / \mathrm{L})$ and had not been prescribed magnesium (93\%). Furthermore, serum magnesium concentrations remained low $(<0.75 \mathrm{mmol} / \mathrm{L})$ when measured during the next acute admission (Fig. 4). These results are consistent with a recent retrospective study $(\mathrm{n}=380)$ that reported a prevalence of low serum magnesium concentrations $(<0.75 \mathrm{mmol} / \mathrm{L})(>60 \%)$ and $17 \%$ 1-year mortality for patients presenting with AWS [9].

The majority of patients $(60 \%)$ who had circulating thiamine diphosphate concentrations above the reference interval (>675 ng/gHb) at the time of study recruitment had been admitted to hospital and treated with parenteral thiamine within 1 month prior to the study related admission. However, in routine clinical practice thiamine concentrations are rarely measured, and if so, results are only available weeks later. Hence, the established clinical appreciation of the importance of thiamine deficiency in exacerbating symptoms in patients with AWS would appear to have resulted in the empirical administration of commercially available thiamine (Pabrinex ${ }^{\circledR}$ ) to patients with AWS admitted to the general hospital setting [12]. In the present cohort of patients, community treatment with oral thiamine combined with the intravenous administration of thiamine during frequent hospital admissions may account for the normal and high circulating concentrations of whole blood thiamine diphosphate observed. In contrast, in the case of magnesium, although results are obtained within minutes/hours of sampling, low serum magnesium concentrations were not routinely supplemented. The infrequency of magnesium supplementation in the context of low serum magnesium concentrations may reflect a lack of clinician awareness that exists regarding the clinical significance and prevalence of magnesium deficiency among AUD patients. This in turn likely reflects a paucity of evidence regarding the prevalence of magnesium deficiency and other micronutrient deficiencies (e.g. vitamin C) among the AUD patient population [36]. Although it has been understood biochemically for decades that thiamine is dependent upon magnesium for optimal metabolism, in the absence of clinical data this has not translated into widespread clinical practice to date.

The measurement and interpretation of thiamine levels is quite problematic and the ideal method remains contentious [37]. Indeed, Cook et al. observed in their review that it was the activity of thiamine, which was relevant, rather than the finite mass available [38]. Erythrocyte transketolase activity (ETKA) is a functional marker of thiamine dependent enzyme activity which was commonly used to measure thiamine status until the late 1990s, however this method of routine measurement of thiamine status fell out of favor due to difficulty with standardization, inter-laboratory variation and the advent of high performance liquid chromatography (HPLC), which enabled direct measurement of TDP mass $[39,40]$. Direct measurement of erythrocyte and/or whole blood thiamine concentrations is now more widely available [35] and has the advantage of remaining consistent in the context of the systemic inflammatory response [41, 42]. Nonetheless, it is of note that significant enhancement of basal erythrocyte transketolase activity (ETKA) has been demonstrated in response to co-administration of thiamine and magnesium, as compared to thiamine alone, in a cohort of alcohol dependent patients [16].

On the basis of the present results, it may be proposed that further studies to elucidate the pharmacokinetics of parenteral thiamine supplementation are required to clarify the safe therapeutic window during which patients with AWS may not require further treatment with 
parenteral thiamine. The basis of Wernicke's encephalopathy (WE) is not clear [18]. However, it is clear that WE is exacerbated by thiamine deficiency $[33,43]$. Under normal physiological and nutritional conditions, the average adult human has approximately a 3-week reserve of thiamine in the liver and skeletal muscle. These reserves become rapidly depleted in alcohol related disease [43, 44]. Therefore, given the present results, it is likely that these patients were compliant with thiamine supplementation as routinely prescribed and confirm the success of a therapeutic strategy for a patient group who are known to be at high risk of thiamine deficiency. Overall, the clinical consequences of under-treating thiamine deficiency are potentially devastating, while treatment with parenteral thiamine appears to have a good safety profile and is relatively inexpensive. However, it is not clear whether chronically high circulating thiamine may have a detrimental effect on health.

The basis of the finding that low serum magnesium concentrations $(<0.75 \mathrm{mmol} / \mathrm{L})$ were independently associated with more severe alcohol withdrawal syndrome (GMAWS $\geq 4$ ) is not clear. However, the present results are in keeping with in vitro data that confirms the role of magnesium in stabilisation of the NMDA receptor [45]. NMDA receptors require binding of glutamate and glycine, combined with the relief of the voltage-dependent magnesium block, to open the calcium ion conductive pore [45]. The association between higher maximal AWS scores (GMAWS max) and low serum magnesium concentrations may reflect the reliance of the NMDA receptor on the stabilizing effect of magnesium (see Table 2) $[46,47]$. Hence, a biochemical cause for AWS related seizure activity may be converted to a structural focus for seizure activity and result in lower subsequent seizure thresholds [46]. This process of alcohol withdrawal 'seizure kindling' may be reflected in the strong association between a documented history of previous alcohol withdrawal seizures that was noted in a high proportion of patients (97\%) who had sustained an alcohol withdrawal seizure in the 12-h period prior to recruitment to the study.

The present study also reports data relating to the interrelationship between thiamine and magnesium status in intermediary metabolism, as reflected in plasma lactate concentrations. Serum magnesium concentrations were significantly associated with plasma lactate concentrations. One possible explanation of the association between low serum magnesium concentrations and raised plasma lactate concentrations, may be that magnesium deficiency mediated compromise of PDH activity can result in pyruvate being unable to gain access into the mitochondrion for conversion to acetyl-CoA and thereby onto Krebs cycle (Figs. 1, 2) [28]. The resulting 'glut' of pyruvate in the cytosol may trigger up-regulation of LDH activity [48]. LDH mediates the increased production of lactate, which accumulates in the cytosol [49]. This may be considered the suboptimal metabolism of glucose i.e. a pseudo-hypoxic 'dirty burn' (Fig. 2) [7]. Given the requirement of $\mathrm{PDH}$ for TDP and magnesium, chronic ingestion of excessive amounts of alcohol in the context of a micronutrient poor diet may therefore result in pseudo-hypoxic dysregulation of glucose metabolism (i.e. 'dirty burn' metabolism) with increased lactate production (Fig. 2) [7, 50].

Interestingly, elevated plasma lactate was significantly associated with 1-year mortality and this may reflect a chronic loss of oxidative resilience among this patient group. Alcohol related cirrhotic liver disease is reported to cause increased splanchnic and systemic plasma lactate concentrations [51], however associations between plasma lactate and serum bilirubin concentrations or plasma lactate concentrations and AST:ALT ratio $>2$ were not significant. Overall, this series of patients would appear to represent the largest cohort of AWS patients to have non-seizure related elevated plasma lactate concentrations recorded to date.

\section{Limitations}

The present study sample may not be representative of all patients experiencing alcohol use disorder. Patients who experience AWS represent a group of AUD patients who have a very high level of dependence and of withdrawal complications. Indeed, the patients described in the present study represent a group of AUD patients who have been treated with previous thiamine supplementation. Furthermore, it is worth considering that in the context of such high dose supplementation, other B-vitamins apart from thiamine (e.g. nicotinamide, pyridoxine and riboflavin) may also be within their normal interval ranges for those patients who receive frequent high dose parenteral therapy. Another important limitation of this study is the lack of measurement of other micronutrients e.g. B-vitamins, vitamin $\mathrm{C}$ and trace elements e.g. selenium and zinc. Further studies that present data relating to more comprehensive nutritional assessment are required in order to better nutritionally phenotype these individuals.

Also, the relatively small sample size $(n=115)$ may be considered a limitation of this study. Nonetheless, this sample presenting prospective data relating to the clinicopathological characteristics of patients experiencing AWS is one of the largest reported to date.

The underlying mechanisms that could explain a relation between low circulating magnesium concentrations and increased all-cause mortality remain to be established. For example, it may be postulated that those 
patients with low circulating magnesium concentrations may have had poorer access to care, therefore they were less likely to be offered supplementation and may have died sooner, but without any direct link between these two conditions. To establish the potential benefit of magnesium supplementation, it will be necessary to carry out a randomised controlled trial of magnesium supplementation in patients with AWS.

\section{Conclusion}

The prevalence of low circulating thiamine concentrations were rare and it was regularly prescribed in patients with AWS. In contrast, low serum magnesium concentrations were common and not prescribed. Low serum magnesium was associated more severe AWS and increased 1 -year mortality.

\begin{abstract}
Abbreviations
AWS: alcohol withdrawal syndrome; TDP: whole blood thiamine diphosphate; $\mathrm{ng} / \mathrm{gHb}$ : nanogram per gram of haemoglobin; $\mathrm{Mg}^{2+}$ : serum magnesium; mmol/L: millimole per litre; GMAWS: glasgow modified alcohol withdrawal scale (); BMI: body mass index; CRP: C-reactive protein; NMDA: N-methylD-aspartate; GABA: gamma-aminobutyric acid; CIWA-Ar: Clinical Institute Withdrawal Assessment-Alcohol Revised; PPi: proton pump inhibitor; AST: aspartate transaminase; ALT: alanine aminotransaminase; LDH: lactate dehydrogenase; MCV: mean corpuscular volume; $r_{s}$ : Spearman correlation.
\end{abstract}

\section{Acknowledgements}

The authors wish to acknowledge assistance obtained from Dr. Roma Armstrong and Dr. Maureen Travers (NHS GGC R\&D) and the support of the nursing staff within the Emergency Department at Glasgow Royal Infirmary.

\section{Authors' contributions}

The authors' contributions were as follows-DM, DCM and DT and conceived the idea; DM, DCM, EF and DT contributed to the study design. DM obtained ethics committee and R\&D approval. DM, GR, DR, JLK, MA, XR, EC, Al, HB and LO: contributed to identification and enrolment of subjects, obtained patient consent and collected the study blood samples; AB, FS, PG and AC: prepared and analysed the blood samples; DM, DY and DCM performed the statistical analysis. DM and DCM were the principal authors of the manuscript. All authors contributed to the manuscript. All authors read and approved the final manuscript.

\section{Funding}

DM received funding from NHS Greater Glasgow and Clyde Research and Development department (NHS GGC R\&D) to undertake this work.

\section{Availability of data and materials}

Data will be made available upon request to the corresponding author.

\section{Ethics approval and consent to participate}

Ethics approval was obtained from the West of Scotland Research and Ethics Committee (WoS REC: 16/WS/0162).

\section{Consent for publication}

Informed consent was obtained from all patients prior to enrolment. Consent for publication has been obtained from all authors.

\section{Competing interests}

The authors declare that they have no competing interests.

\section{Author details}

1 Emergency Medicine Department, Glasgow Royal Infirmary, 84 Castle Street, Glasgow G4 OSF, Scotland, UK. ${ }^{2}$ Academic Unit of Surgery, School of Medicine,
University of Glasgow, New Lister Building, Royal Infirmary, Glasgow G31 2ER, Scotland, UK. ${ }^{3}$ The Scottish Trace Element and Micronutrient Diagnostic and Reference Laboratory, Department of Biochemistry, Royal Infirmary, Glasgow G31 2ER, Scotland, UK. ${ }^{4}$ Department of Biochemistry, Queen Elizabeth University Hospital, Glasgow G51 4TF, Scotland, UK. ${ }^{5}$ Department of Mathematics and Statistics, University of Strathclyde, 26 Richmond Street, Glasgow G1 1XH, Scotland, UK. ${ }^{6}$ Department of Gastroenterology, Glasgow Royal Infirmary, Glasgow G4 OSF, Scotland, UK.

Received: 5 August 2019 Accepted: 15 November 2019

Published online: 21 November 2019

\section{References}

1. Gilmore W, Chikritzhs T, Stockwell T, Jernigan D, Naimi T, Gilmore I. Alcohol: taking a population perspective. Nat Rev Gastroenterol Hepatol. 2016;13(7):426-34.

2. Organization. WHO. Global status report on alcohol and health (WHO, 2014). http://www.who.int/substance_abuse/publications/global_alcoh ol_report/msb_gsr_2014_1.pdf?ua=1.

3. Mokdad AH, Ballestros K, Echko M, Glenn S, Olsen HE, Mullany E, et al. The State of US Health, 1990-2016: burden of diseases, injuries, and risk factors among US States. JAMA. 2018:319(14):1444-72.

4. Collaborators GA. Alcohol use and burden for 195 countries and territories, 1990-2016: a systematic analysis for the Global Burden of Disease Study 2016. Lancet. 2018;392(10152):1015-35.

5. Statistics ON. Alcohol specific deaths in the UK: registered in 2017. https ://www.ons.gov.uk/peoplepopulationandcommunity/healthandsocial care/causesofdeath/bulletins/alcoholrelateddeathsintheunitedkingdom/ registeredin2017.

6. McPherson A, Benson G, Forrest EH. Appraisal of the Glasgow assessment and management of alcohol guideline: a comprehensive alcohol management protocol for use in general hospitals. QJM. 2012;105(7):649-56.

7. Maguire D. An investigation into the role of thiamine and magnesium in the pathophysiology and treatment of alcohol withdrawal syndrome. Glasgow: University of Glasgow; 2019.

8. Das SK, Vasudevan DM. Alcohol-induced oxidative stress. Life Sci. 2007:81(3):177-87.

9. Maguire D, Ross DP, Talwar D, Forrest E, Abbasi HN, Leach JP, et al. Low serum magnesium and 1-year mortality in alcohol withdrawal syndrome. Eur J Clin Invest. 2019:49:e13152.

10. Perry EC. Inpatient management of acute alcohol withdrawal syndrome. CNS Drugs. 2014;28(5):401-10.

11. Amato L, Minozzi S, Davoli M. Efficacy and safety of pharmacological interventions for the treatment of the alcohol withdrawal syndrome. Cochrane Database Syst Rev. 2011;6:CD008537.

12. NICE. Alcohol-use disorders: diagnosis and management of physical complications. 2017.

13. Flannery AH, Adkins DA, Cook AM. Unpeeling the evidence for the banana bag: evidence-based recommendations for the management of alcohol-associated vitamin and electrolyte deficiencies in the ICU. Crit Care Med. 2016;44(8):1545-52.

14. Osiezagha K, Ali S, Freeman C, Barker NC, Jabeen S, Maitra S, et al. Thiamine deficiency and delirium. Innov Clin Neurosci. 2013;10(4):26-32.

15. Onozuka M, Nosaka K. Steady-state kinetics and mutational studies of recombinant human thiamin pyrophosphokinase. J Nutr Sci Vitaminol (Tokyo). 2003;49(3):156-62.

16. Peake RW, Godber IM, Maguire D. The effect of magnesium administration on erythrocyte transketolase activity in alcoholic patients treated with thiamine. Scott Med J. 2013;58(3):139-42.

17. Sevostyanova IA, Yurshev VA, Solovjeva ON, Zabrodskaya SV, Kochetov GA. Effect of bivalent cations on the interaction of transketolase with its donor substrate. Proteins. 2008;71(2):541-5.

18. Hazell AS, Faim S, Wertheimer G, Silva VR, Marques CS. The impact of oxidative stress in thiamine deficiency: a multifactorial targeting issue. Neurochem Int. 2013;62(5):796-802.

19. Pilchova I, Klacanova K, Tatarkova Z, Kaplan P, Racay P. The Involvement of $\mathrm{Mg}(2+)$ in regulation of cellular and mitochondrial functions. Oxid Med Cell Longev. 2017;2017:6797460. 
20. Sweet RL, Zastre JA. HIF1-a-mediated gene expression induced by vitamin B1 deficiency. Int J Vitam Nutr Res. 2013;83(3):188-97.

21. Thomson AD, Marshall EJ. The natural history and pathophysiology of Wernicke's Encephalopathy and Korsakoff's Psychosis. Alcohol Alcohol. 2006:41(2):151-8.

22. Donnino MW, Vega J, Miller J, Walsh M. Myths and misconceptions of Wernicke's encephalopathy: what every emergency physician should know. Ann Emerg Med. 2007;50(6):715-21.

23. Thomson AD, Cook CC, Touquet R, Henry JA, Royal College of Physicians Ln. The Royal College of Physicians report on alcohol: guidelines for managing Wernicke's encephalopathy in the accident and Emergency Department. Alcohol Alcohol. 2002;37(6):513-21.

24. Dingwall KM, Delima JF, Gent D, Batey RG. Hypomagnesaemia and its potential impact on thiamine utilisation in patients with alcohol misuse at the Alice Springs Hospital. Drug Alcohol Rev. 2015;34(3):323-8.

25. Traviesa DC. Magnesium deficiency: a possible cause of thiamine refractoriness in Wernicke-Korsakoff encephalopathy. J Neurol Neurosurg Psychiatry. 1974;37(8):959-62.

26. Zieve L. Influence of magnesium deficiency on the utilization of thiamine. Ann N Y Acad Sci. 1969;162(2):732-43.

27. McLean J, Manchip S. Wernicke's encephalopathy induced by magnesium depletion. Lancet. 1999:353(9166):1768.

28. Ciszak EM, Korotchkina LG, Dominiak PM, Sidhu S, Patel MS. Structural basis for flip-flop action of thiamin pyrophosphate-dependent enzymes revealed by human pyruvate dehydrogenase. J Biol Chem. 2003;278(23):21240-6.

29. Lonsdale D. Three case reports to illustrate clinical applications in the use of erythrocyte transketolase. Evid Based Complement Alternat Med. 2007:4(2):247-50

30. Krishnadas R, McLean J, Batty GD, Burns H, Deans KA, Ford I, et al. Socioeconomic deprivation and cortical morphology: psychological, social, and biological determinants of ill health study. Psychosom Med. 2013;75(7):616-23.

31. Shipton $D$, Whyte $B$, Walsh D. Alcohol-related mortality in deprived UK cities: worrying trends in young women challenge recent national downward trends. J Epidemiol Commun Health. 2013;67(10):805-12.

32. Formulary BN. Pabrine ${ }^{\circledR}$ 2017. http://services2.ascribe.com:8080/bnf/ view/page/bnf/PHP6204

33. Thomson AD, Marshall EJ. BNF recommendations for the treatment of Wernicke's encephalopathy: lost in translation? Alcohol Alcohol. 2013;48(4):514-5.

34. Excellence NloC. Vitamin B substances with ascorbic acid 2019. https:// bnf.nice.org.uk/drug/vitamin-b-substances-with-ascorbic-acid.html.

35. Talwar D, Davidson H, Cooney J, O'Reilly D. Vitamin B(1) status assessed by direct measurement of thiamin pyrophosphate in erythrocytes or whole blood by HPLC: comparison with erythrocyte transketolase activation assay. Clin Chem. 2000;46(5):704-10.

36. Marik $P E$, Liggett A. Adding an orange to the banana bag: vitamin $C$ deficiency is common in alcohol use disorders. Crit Care. 2019;23(1):165.

37. Whitfield KC, Bourassa MW, Adamolekun B, Bergeron G, Bettendorff $L$, Brown $\mathrm{KH}$, et al. Thiamine deficiency disorders: diagnosis, prevalence, and a roadmap for global control programs. Ann NY Acad Sci. 2018;1430(1):3-43.

38. Cook CC, Hallwood PM, Thomson AD. B Vitamin deficiency and neuropsychiatric syndromes in alcohol misuse. Alcohol Alcohol. 1998;33(4):317-36.

39. Baines M, Davies $G$. The evaluation of erythrocyte thiamin diphosphate as an indicator of thiamin status in man, and its comparison with erythrocyte transketolase activity measurements. Ann Clin Biochem. 1988;25(Pt 6):698-705

40. Baines M. Improved high performance liquid chromatographic determination of thiamin diphosphate in erythrocytes. Clin Chim Acta. 1985;153(1):43-8.

41. Quasim T, McMillan DC, Talwar D, Vasilaki A, O'Reilly D, Kinsella J. The relationship between plasma and red cell B-vitamin concentrations in critically-ill patients. Clin Nutr. 2005;24(6):956-60.

42. Ghashut RA, McMillan DC, Kinsella J, Talwar D. Erythrocyte concentrations of $B 1, B 2, B 6$ but not plasma $C$ and $E$ are reliable indicators of nutrition status in the presence of systemic inflammation. Clin Nutr ESPEN. 2017;17:54-62.

43. Thomson AD, Marshall EJ, Bell D. Time to act on the inadequate management of Wernicke's encephalopathy in the UK. Alcohol Alcohol. 2013;48(1):4-8.

44. Thomson AD, Guerrini I, Marshall EJ. The evolution and treatment of Korsakoff's syndrome: out of sight, out of mind? Neuropsychol Rev. 2012:22(2):81-92.

45. Zhu S, Stein RA, Yoshioka C, Lee CH, Goehring A, Mchaourab HS, et al. Mechanism of NMDA receptor inhibition and activation. Cell. 2016;165(3):704-14.

46. Hillbom M, Pieninkeroinen I, Leone M. Seizures in alcohol-dependent patients: epidemiology, pathophysiology and management. CNS Drugs. 2003;17(14):1013-30.

47. Mortadza SS, Sim JA, Stacey M, Jiang LH. Signalling mechanisms mediating Zn(2+)-induced TRPM2 channel activation and cell death in microglial cells. Sci Rep. 2017;7:45032.

48. Liu D, Ke Z, Luo J. Thiamine deficiency and neurodegeneration: the interplay among oxidative stress, endoplasmic reticulum stress, and autophagy. Mol Neurobiol. 2016;54(7):5440-8.

49. Sugden MC, Holness MJ. Recent advances in mechanisms regulating glucose oxidation at the level of the pyruvate dehydrogenase complex by PDKs. Am J Physiol Endocrinol Metab. 2003;284(5):E855-62.

50. Maguire D, Talwar D, Shiels P, McMillan D. The role of thiamine dependent enzymes in obesity and obesity related chronic disease states: a systematic review. Clin Nutr ESPEN. 2018;25:8-17.

51. Jeppesen JB, Mortensen C, Bendtsen F, Møller S. Lactate metabolism in chronic liver disease. Scand J Clin Lab Invest. 2013;73(4):293-9.

\section{Publisher's Note}

Springer Nature remains neutral with regard to jurisdictional claims in published maps and institutional affiliations.

Ready to submit your research? Choose BMC and benefit from:

- fast, convenient online submission

- thorough peer review by experienced researchers in your field

- rapid publication on acceptance

- support for research data, including large and complex data types

- gold Open Access which fosters wider collaboration and increased citations

- maximum visibility for your research: over $100 \mathrm{M}$ website views per year

At BMC, research is always in progress.

Learn more biomedcentral.com/submissions 